\title{
29
}

\section{OIKOS INTERNATIONAL AND THE DECADE OF ACTION}

\section{Oliver Braunschweig, Giuliana Longworth and J. Christopher Proctor}

oikos International ("oikos") is an international student organization which promotes sustainability in economics and management education. We were founded over 30 years ago in St. Gallen, Switzerland, and have since then expanded into a network of over 45 chapters based at universities around the world. In addition, oikos includes the broader community of alumni, partners, advisors, and friends.

For this chapter, we tried to look forward to 2030 and think about a world in which - despite the long odds - we had somehow achieved the Sustainable Development Goals. Then we tried working backward to see what had to happen to make the "Decade of Action" a success, first in the world, then in management education and finally within oikos.

\subsection{Looking toward 2030}

As we write this chapter in April 2020, COVID-19 has swept the world. As students, we have seen our campuses closed and our universities thrown into confusion. As members of oikos, we have been forced to call off our 
in-person gatherings and have begun to plan for how to sustain student groups and their projects through an extended lockdown. As citizens, we have seen critical weaknesses in our global political and economic systems play out on a grand scale: failures in coordinating a response between governments, businesses, and civil society have led to a global disaster.

With ten years left to achieve the Sustainable Development Goals, this is not exactly the start the world's leaders had in mind when they declared a "Decade of Action." Far from racing to tackle the numerous problems the SDGs were designed to address, the world is now struggling to mitigate a disaster that did not even have a name mid-2019.

In the span of weeks, we have seen parts of the world dramatically reorganize themselves to adapt to the new realities created by the virus. The pandemic and the response have laid bare and exacerbated preexisting inequalities and vulnerabilities, with the situation of frontline communities, working families, and the elderly being particularly dire. And yet we take a bit of solace in the fact that so many people worldwide - no matter how imperfectly - have come together to combat this jointly.

Many of us students have lived our entire lives with the understanding that we were in the middle of an unprecedented ecological emergency toward which the world continued running with eyes half-closed. To be sure, despite the photos of smog-free skylines or wildlife returning to city streets, this crisis has not prompted a meaningful change of course regarding ecological sustainability. And the response to the virus itself has decidedly been a mixed bag. Still, in this moment, we cannot but feel hopeful that our species might come together and choose a more sustainable path.

And so, while stuck in quarantine, we started to look to the world of 2030 and dream of what could be. We asked ourselves three daunting but essential questions. First, we interrogated ourselves about the changes the world would need to undergo to accomplish such a transformation. Second, we tried to identify changes in the field of management education which we believed to be indispensable to setting up a globally sustainable human society. Finally, we looked at how oikos International, through its initiatives and programs, can help achieve that change in management education and, as a result, in the world.

To answer these three questions, we turned to the oikos community with an open-ended survey. 20 students and alumni (collectively "oikees"), from 13 different chapters answered. These answers fueled our own discussions and thus form the bedrock of this chapter. 
In this article we are attempting to embed the role of oikos in the task of achieving the SDGs. This is why we start with a discussion of macro-systemic relationships which we identify as relevant for achieving the SDGs. Then our focus moves to the subsystem of management education to see how it could better help achieve the SDGs. Lastly, at the micro-level, we take stock of the programs of oikos and how these are already affecting the meso- and the macro-picture we described in the preceding parts.

Ultimately, this paper is in part a reflection on what oikos is doing, and where it is situated in the larger systematic changes necessary for effective change, and in part it is an invitation to other organizations, academics, and students to join with us in this endeavor.

\subsection{Global Decade of Action}

In our survey, we asked oikees what needs to happen to achieve the SDGs by 2030 . We grouped the different ideas mentioned into larger categories, counting how many different respondents mentioned these categories (see percentages in Figure 29.1 below, see Box 29.1 for methodological examples of aggregation). We then discussed how these categories may positively reinforce each other. The diagram below therefore is the sum of (1) the particular aggregate view of these oikos students onto where changes need to happen to achieve the SDGs, and (2) our discussions about how these changes may interrelate. Bold arrowpoints describe the main causal direction of reinforcement, with hollow circles as the starting point. If we surmised a weaker opposite causal force, we replaced the hollow circles with hollow arrowpoints.

This system has no claim to completeness. Rather, it is a glimpse into the kinds of thinking which oikos as a network strengthens and reinforces.

\subsubsection{Mapping (sub-)systems of change}

We then grouped the arrows into different categories of causal relations, resulting in five "subsystems of change": Education, Governance, Policy, Economic Demand, and Technology. Notice that these subsystems describe a larger self-reinforcing system. 
What Needs to Happen for the World to Achieve the SDGs by 2030?

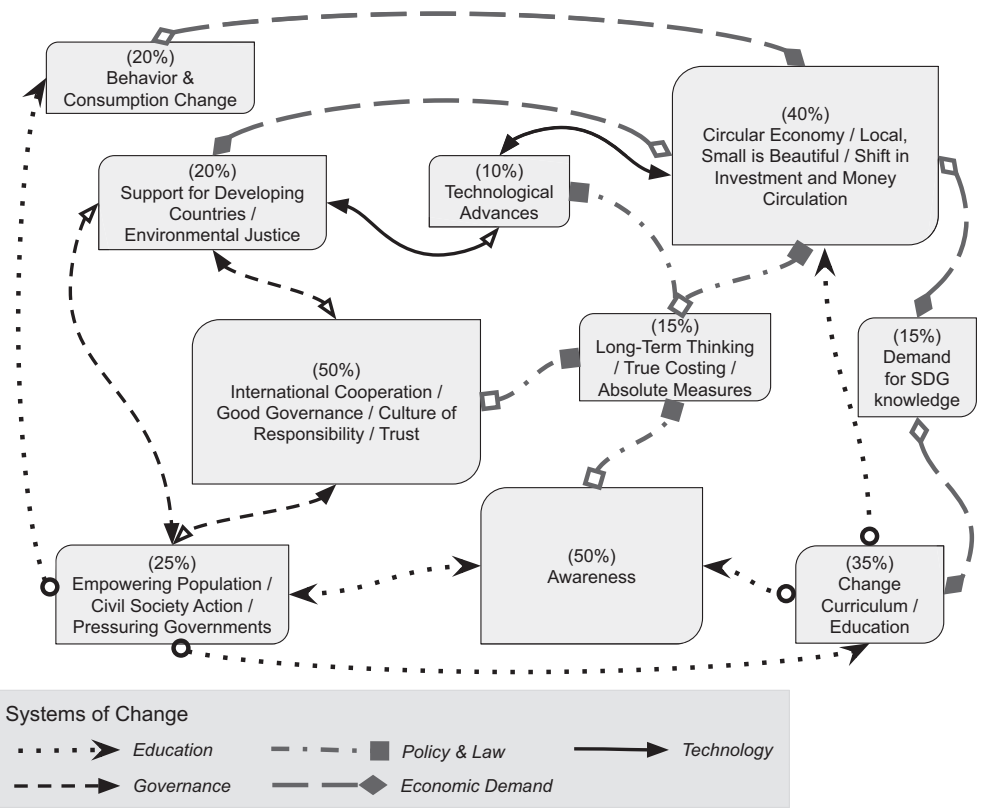

Figure 29.1 What needs to happen for the world to achieve the SDGs by 2030 ?

\section{Box 29.1 METHODOLOGY EXAMPLE}

In this box you will find three quoted answers from the survey exemplifying our iterative approach: In a first step, we took notice of important ideas (bolded). Then we grouped them into concepts [see bracketed terms], combining similar ones into larger encompassing concepts (e.g., below: "Circular Economy/Shift in Investment").

Create more awareness [Awareness] and include the sustainability aspects more into the curriculum/education [Change Education].

A significant majority of people actually caring [Awareness] about what's going on and supporting counteraction [Civil Society Action]. $A$ policy focus on absolute instead of relative measures (tons of $\mathrm{Co} 2$ emitted instead of $\mathrm{CO}_{2}$ per unit of GDP) [Absolute Measures]. Wide 
adoption of a universally circular economy mindset: you can't take more than you give [Circular Economy].

In order to achieve the SDGs, emphasis needs to be placed on moving financing towards sustainable projects [Circular Economy/ Shift in Investment...]. There needs to be a regulatory shift where green energy, sustainable cities, and climate change solutions are prioritized. Along with this, individual and institutional investors should be encouraged to invest their money in companies that have the opportunity to solve our common problems. This requires both a systematic shift as well as the change in individual's personal choices [Behavior Change].

Awareness and good governance were most mentioned (each ten times). Second were sustainable economy (eight mentions) and curriculum change (seven mentions). Empowering civil society (five mentions), as well as support for the less powerful, and behavior changes (each four mentions) were also relatively important.

The fact that public knowledge, (international) governance, and the economic system loom large stands in a clear relation to the studies of oikees (largely students studying management and economics). We believe that change can have multiple origins, so we decided to shape the path of the Decade of Action not as a sequential list of steps, or a list of separate objectives, but as a set of interlinking selfreinforcing sub-systems.

The education system and the governance system both stand out as comprising internal self-reinforcing loops. Regarding the Education system we made sense of this by arguing that knowledge may itself create demand for more knowledge as well as for action. Regarding the good-governancesystem, we surmised that it may self-reinforce, since increased cooperation builds trust, and trust enables better cooperation.

The Policy and Economic Demand arrow-systems can be understood as two sets of avenues through which changes in education and governance can influence both the economy as well as the development of new technologies, i.e. through public or private channels. 
In our mind, the Policy-subsystem includes all of the ways in which civil society, governments, unions, or NGOs could impact the goal-setting and the benchmarking in the economy and of the whole society. This system also includes the laws which govern what is legal, and it is the system in which we are active as citizens and workers, defining through governance systems how our economic system is supposed to work. In other words, the policy arrows show the mixed influences onto (economic) decision-making which do not take the route of economic demand, but could be understood as push-factors for development. It is important to mention here that the concept at the center of this system (Long-Term Thinking, True Costing/Absolute Measures) includes ideas of how we are supposed to define the goals for society: the goals need to include a long-term view, they need to emphasize the internalization of currently externalized costs, and they need to be measured in absolute terms (rather than per capita).

The web of arrows elucidates the connections which economic demand creates: public pressure and private demand, as well as the demands of companies affecting their supply chains and the pressure on changing the educational systems to reflect the need for new expertise. Whereas the Policy system describes our action-routes as organized citizens and workers, the Economic Demand side shows the powers of demand in supply chains: consumption impacting production and trade. Ultimately, Economic Demand points back to education itself, since a changed economy will demand differently educated citizens and workers.

A final subsystem shows how technical change is both a reflection of the developments in the economic sector and how technological change itself influences the realm of the (economically) possible. An idea we discussed here is that the existence of a technology does not necessarily lead to its successful adoption, nor are technologies by themselves the crucial ingredient to achieving the SDGs. Rather, technologies are tools, and their effects are guided by their specific use, e.g. whether more renewable energies will lead to a reduction in $\mathrm{CO}_{2}$ exhaust or whether they will just be added to production and thus lead to cheaper energy and higher use (rebound effect), is a question of policy, not of technology. We furthermore argue that when technologies are shared, they also support developing countries. They thus may have positive effects on environmental justice, and thus potentially play a positive role in the realm of national and international governance, trust, and civil society empowerment. 
These systems of arrows show the perception of students focusing on sustainable development: The economy is not primarily described as a motor of change in itself, but rather as that which we are aiming to change through education and good governance.

\subsubsection{Missing links}

There are several important aspects which this diagram does not cover, because the question asked was not related to them: the speed necessary for these changes, the actual iniquities and inequalities which the SDGs were designed to change, and possible conflicts between the different SDGs. Furthermore, as it stands now, some of the achievements of the last decade (like poverty reductions and more) are very drastically being undone by the fallout from the current pandemic.

While we do not know exactly how fast the change should be, we do believe that the change necessary is massive. In the face of a clear consensus that we are steering toward a global climate crisis, that toxicities in the world continue to build up, and that the loss of soil and biodiversity is at an unprecedented rate, the question is not one of whether we should be a bit faster or a bit slower. The question is how we can design a system of change which will help us achieve these goals without having to choose between any of the SDGs.

Our chart actually captures our cautious optimism. The pandemic is highly destructive, but we hope that it will also show our strong interdependence as humans, and our connection as a species to this planet and its other living entities. We hope and believe that the understanding that we are in this together - and that the world needs neighborly help to get through this as well as possible - will also create a base on top of which we will be able to build a more equitable and sustainable society.

\subsection{Decade of Action for management education}

oikos members clearly see education as one of the key systems that need to change to put the world on the path to achieving the SDGs. In this section, we'll zoom down into the "curriculum change/education" box from Figure 29.1 to see what exactly oikees have in mind when it comes to changing management education. 
In our survey, we asked oikees "How would management education have to change to help achieve the SDGs. For respondents who did not study management, we asked them to also include thoughts on how their disciplines need to change. Half of the respondents reported Management as their primary field of study, 30\% listed economics, and the rest studied related fields (international relations, political science, sustainable finance, and geography). We asked for responses to be limited to three key suggestions. Using the same process as in the previous section, we drew out key themes and suggestions from the responses and visualized them in Figure 29.2. The numbers in each box show the percentage of responses which mentioned an idea.

In this case, the responses did not show a clear flow or direction, but instead seemed to address three broad levels at which the changes would take place: within the classroom, within the curriculum and within the university. Changes in the classroom refer primarily to the teaching methods of how information is conveyed to students, while changes to the curriculum speak to the actual content taught within a study program. Changes

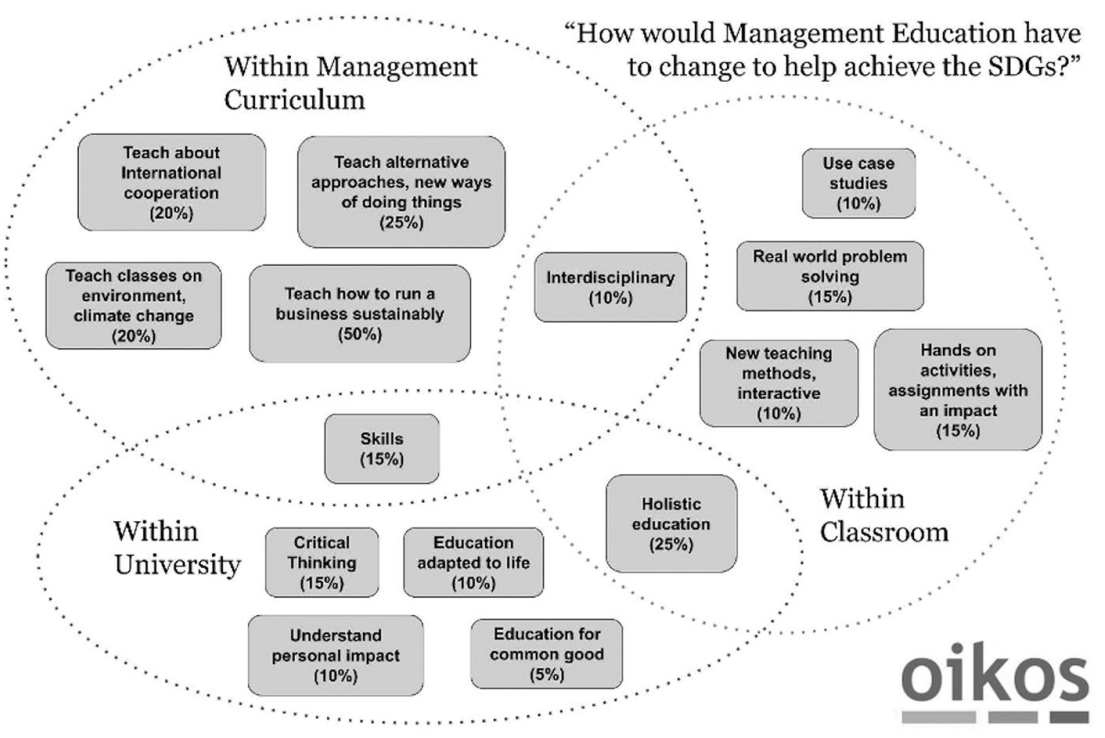

Figure 29.2 How would management education have to change to help achieve the SDGs? 
within the university include broader topics like the ultimate goals of education and students' overall educational experience.

The most common responses addressed changes within the curriculum, with students suggesting a number of possible alterations to the standard academic content taught within a management degree. The most popular single response, by far, was that management education needs to teach students how to run a business sustainably. On a more specific level, respondents wanted to learn alternative economic and management theories, with models like the circular economy and the triple bottom line coming up multiple times. Reflecting the responses shown in Figure 29.1, students also requested more content related to international cooperation and the problem of climate change, particularly from a scientific perspective.

Students also had a number of suggestions regarding how classes were taught, with responses focusing on the need for interactive teaching methods which connected academic material with the real world. In particular, students seemed excited about the possibility of doing hands-on activities during their studies which could have a real impact in their communities.

Finally, some responses spoke more broadly to the overall goals of an education, which they believed should be used to develop critical thinking skills and a better understanding of our personal impact on the world. There were also requests that management education adopt more flexible class schedules to be better adapted to the personal and professional needs of students.

A few topics did not fall neatly into these divisions and were placed between the categories. "Skills" seemed to include both suggestions that classes teaching skills like leadership be included in the curriculum, but also that learning and practicing skills be treated as a core goal of a university education. Similarly, "Holistic education" included both suggestions that topics were taught in a holistic way within individual classes and that entire degree programs are designed to produce a holistic education. Finally, the suggestion of "Interdisciplinary" referred both to teaching courses from other disciplines within a management degree and to integrating an interdisciplinary approach within management specific classes.

Figure 29.2 provides a good summary of the kind of changes oikos students want to see from management education. It also provides a rough road map for where they need to go to make those changes, for while there are certainly deviations from country to country and university to 
university, changes at each level are typically the responsibility of a similar group of people. To change things within the classroom, students need to go to their teachers, who often have a good deal of control over the specific teaching methods they use in their courses. To change the overall curriculum, students need to work with groups of management faculty, either on curriculum committees or in departmental leadership roles. And to change the bigger goals of education, students need to address administrators like deans or university presidents who are involved with setting the strategy and operation guidelines for the entire university or business school.

Achieving all of this is no small task, especially for students who are still busy earning their degree. But the framework does make the specific task of "curriculum change" more comprehensible and is useful for building programs within oikos international to support students to work at each of the three levels.

\section{4 oikos: students transforming education}

In our first section we looked at several systems of change and identified what we believed to be main fields of action. Within the educational system of change three main subcategories were highlighted: (1) empowering population/civil society action/pressuring governments, (2) awareness, and (3) change curriculum/education.

Interestingly enough, oikos is structured to respond to the system challenges faced by the world by addressing the same specific leverages found in our survey. As stated by its mission, oikos aims to transform economics and management education by (1) empowering student change agents, (2) raising awareness for sustainability opportunities and challenges, and (3) building institutional support for curriculum reform.

Through the following initiatives and programs, oikos aims to achieve a change in economics and management education and therefore to be part of the transition into a more sustainable world (see a shorter overview in Box 29.2).

\subsubsection{Local chapters organizing for change}

The vast majority of oikos' work takes place in its chapters at the local level. It is there that students hold lectures and essay contests, host film 


\section{Box 29.2 SELECTED PROGRAMS AND ACTIVITIES OF OIKOS INTERNATIONAL}

- Local chapters organizing for change: oikos Chapters, oikos Winter and Summer Schools, and oiConference on Sustainable Finance

- Supporting curriculum changers: oikos Curriculum Academies

- Understanding management education: Positive Impact Rating and oikos in Residence

- Promoting good practices: oikos Case Program

- Connecting people: FutureLab, Regional Meetings, and Spring Meetings

- Training leaders: oikos Leadership Program - LEAP

- Promoting research: oikos Research Fellowships and oikos-PRME Research Hub

screenings and sustainable fashion shows, and do more. Multiplied across our nearly 50 chapters, this stream of local events and activities reaches thousands of management and economics students each year.

Chapters are also increasingly becoming directly involved in working to change education at their own universities, with multiple chapters setting up Curriculum Transformation teams. These survey students, review programs, and/or work with faculty and administration to integrate sustainability into their programs. Some chapters have even been invited by their faculty to directly give lectures on sustainability within existing courses, and at least one chapter is already working directly with the PRME team located at their university.

\subsubsection{Supporting curriculum changers}

Advocating for curriculum change can be quite challenging for students, particularly for those getting involved for the first time. To lower this barrier, oikos International has a number of programs designed to empower students and to help them facilitate transformation within their own courses.

For example, by providing a chance to interact with experts in the field.

For example the oikos Curriculum Academies ${ }^{1}$ create space for students and researchers to interact with experts in the field and learn about 
innovative programs as well as teaching approaches which are designed to address current global environmental and social challenges. oikos also organizes regular calls where oikees can learn from each other by presenting and discussing their projects aimed at changing the curriculum at their university.

\subsubsection{Understanding management education}

oikos also seeks to better understand management education by engaging in and supporting various research projects. We are one of the leading and founding partners of the Positive Impact Rating, ${ }^{2}$ an annual report assessing business schools' value for the world.

Another question oikees are tackling is what exactly we think management education should look like. In effect, they are zooming deeper into the "within management curriculum" section on Figure 29.2 to imagine a new kind of business education.

To do this, they have created a "Design Your Own Curriculum" project which is mapping out the core building blocks of business education to provide a "do it yourself" kit for creating a sustainable business degree (see Figure 29.3 for their provisional Building Blocks).

oikos has also created a new event format, the oikos in Residence, to facilitate and accelerate international research projects like this.

\subsubsection{Promoting good practices}

Case studies are a powerful tool to illustrate theories and to apply principles and innovative methods. Not only do case studies bridge the divide

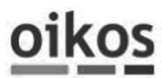

Theoretical

\begin{tabular}{|c|c|c|}
\hline \multicolumn{1}{c|}{ Contextual } & Practical & Organizational Varieties \\
\hline $\begin{array}{c}\text { Introducing Business } \\
\begin{array}{c}\text { Global Challenges and } \\
\text { Trends }\end{array}\end{array}$ & $\begin{array}{c}\text { Personal \& Professional } \\
\text { Development }\end{array}$ & $\begin{array}{c}\text { Political-Economic } \\
\text { Systems }\end{array}$ \\
\hline
\end{tabular}

Figure 29.3 Provisional "building blocks of business education" from the oikos design your own curriculum project. 
between research and practice, but they also offer straightforward and practical guidelines for changing existing structures and their modus operandi. These case studies are part of a shifting from the traditional lecture to a more interactive and dynamic educational approach which maximizes learning and course performance.

oikos has been helping introduce case studies into courses through its Case Program initiative since 2003. This initiative encourages the writing of high-quality cases on sustainability topics, it stimulates innovative teaching and learning, and invites students to approach their faculty to embed sustainability into their curricula. Each case study is, in fact, submitted with a Teaching Note, helping staff introduce the case studies into their classes.

\subsubsection{Connecting people}

Networking opportunities help integrate sustainability in economics and management curricula. They allow people with similar values and principles to build the networks necessary for working together toward these shared goals.

oikos provides space for such exchanges of ideas, perspectives, and experiences in its FutureLab, ${ }^{3}$ Regional Meetings, ${ }^{4}$ and Spring Meetings. ${ }^{5}$ At these, oikees from all over the world come together to learn, discuss, and share. In postevent feedback, oikees often express how these experiences inspire more action on their part.

\subsubsection{Training leaders}

Developing leadership capabilities is fundamental when empowering change agents and is a core part of the oikos mission. Providing the tools to act as a leader and to initiate change can generate significant long-term impact and ensure the sustainability of actions. In this way, leadership programs inspire young people to become more responsible and sustainable in their decision making and equip them with the insights, knowledge, and tools to do so.

oikos International offers such an opportunity in its oikos Leadership Program - LEAP. ${ }^{6}$ The program not only challenges participants to reflect on their values, purpose, and actions but empowers them to be proactive about change. 
Since its launch in 2015, the program has welcomed over 250 participants and has had a lasting influence on the participants' lives. Many "LEAPers" return to the program as coaches to continue their leadership journey and help a new generation of participants in the process.

\subsubsection{Promoting research}

Research challenges accepted ideas, and can help us adapt and create community values related to sustainability and its impact. By providing an understanding of the potential impacts of applying sustainable goals to management and economics, research contributes to building a solid base for action.

To support research in this field, oikos international has had partnerships with universities to offer oikos Research Fellowships, ${ }^{7}$ providing $\mathrm{PhD}$ students with support in writing their thesis on sustainability and with an opportunity to engage in oikos programs.

To support collaboration among researchers, oikos has jointly established the oikos-PRME Research Hub. ${ }^{8}$ This Hub provides a platform where students can publish finalized or ongoing research on sustainability in economics, finance, and management. By hosting the Hub jointly, oikos and PRME are able to allow quality student research to flow across our next works to inform and inspire.

\section{Notes}

1 More information available at: https://oikos-international.org/programs/ curriculum-change-initiative/oikos-academy-2020/

2 More information available at: https://www.positiveimpactrating.org/

3 See more information at: https://oikos-international.org/programs/ international-conferences/futurelab/

4 See more information at: https://oikos-international.org/programs/regionalmeetings/

5 See more information at: https://oikos-international.org/programs/ international-conferences/spring-meeting/

6 Seemoreinformationat:https://oikos-international.org/programs/leadershipprogram-leap/ 
7 See more information at: https://oikos-international.org/programs/ research-fellowship/https://oikos-international.org/programs/ research-fellowship/

8 See more information at: https://oikos-international.org/programs/ curriculum-change-initiative/oikos-prme-research-hub/ 